\title{
Role of transition metal exporters in virulence: the example of Neisseria meningitidis
}

\section{Cyril Guilhen, Muhamed-Kheir Taha and Frédéric J. Veyrier*}

Département Infection et Epidémiologie, Institut Pasteur, Unité des Infections Bactériennes Invasives, Paris, France

\section{Edited by:}

Mathieu F. Cellier, Institut National de la Recherche Scientifique,

Canada

\section{Reviewed by:}

Caroline Genco, Boston University

School of Medicine, USA

Thomas Kehl-Fie, University of

Illinois, USA

\section{*Correspondence:}

Frédéric J. Veyrier, Département Infection et Epidémiologie, Institut Pasteur, Unité des Infections Bactériennes Invasives, 28 Rue du Dr. Roux, 75015 Paris, France e-mail:veyrier@pasteur.fr
Transition metals such as iron, manganese, and zinc are essential micronutrients for bacteria. However, at high concentration, they can generate non-functional proteins or toxic compounds. Metal metabolism is therefore regulated to prevent shortage or overload, both of which can impair cell survival. In addition, equilibrium among these metals has to be tightly controlled to avoid molecular replacement in the active site of enzymes. Bacteria must actively maintain intracellular metal concentrations to meet physiological needs within the context of the local environment. When intracellular buffering capacity is reached, they rely primarily on membrane-localized exporters to maintain metal homeostasis. Recently, several groups have characterized new export systems and emphasized their importance in the virulence of several pathogens. This article discusses the role of export systems as general virulence determinants. Furthermore, it highlights the contribution of these exporters in pathogens emergence with emphasis on the human nasopharyngeal colonizer Neisseria meningitidis.

Keywords: virulence factors, Neisseria meningitidis, metals, exporter, efflux

\section{INTRODUCTION}

For decades, it has been known that transition metals played a role in regulating host pathogen relationships (Weinberg, 1971; Finkelstein et al., 1983). Bacterial pathogens must acquire these metals in order to survive in the host during an infection. Metals such as Fe, Mn, Zn, Ni, Cu, Co, and Mo (Schaible and Kaufmann, 2005) have an incomplete " $d$ " orbital which permits different states of oxidation, e.g., $\mathrm{Fe}^{2+}$ and $\mathrm{Fe}^{3+}$. These metals often serve essential roles in protein structural stabilization or as enzymes cofactors (Barondeau and Getzoff, 2004). However, the unique chemistry of these metals can also provoke inappropriate redox reactions with $\mathrm{O}_{2}^{-}$and $\mathrm{H}_{2} \mathrm{O}_{2}$, (Fenton's reaction), generating highly damaging hydroxyl radicals $\left(\mathrm{OH}\right.$ and $\left.\mathrm{OH}^{-}\right)$that can ultimately lead to the cell death (Stadtman, 1990). It is perhaps this duality that has driven the selection of sophisticated bacterial strategies to orchestrate transition metal homeostasis by sensing, acquiring, storing, or when necessary, exporting these essential but potentially lethal metals.

The stringent and complex requirements of bacterial pathogens for metals have been exploited by the immune system to limit bacterial growth. The majority of described examples demonstrate that the immune system uses starvation strategies that consist in decreasing metal availability (mainly $\mathrm{Fe}^{2+}, \mathrm{Zn}^{2+}$, and $\mathrm{Mn}^{2+}$ ) (Canonne-Hergaux et al., 1999; Corbin et al., 2008) to restrict bacterial growth. However, recent reports suggest the existence of an immune strategy whereby the bacteria are poisoned with an overload of metal, principally $\mathrm{Zn}^{2+}$ and $\mathrm{Cu}^{+/ 2+}$ (White et al., 2009). This latter finding also corroborates the fact that deletion of bacterial efflux pumps often impairs the virulence of pathogens (Stahler et al., 2006; Rosch et al., 2009; Botella et al., 2011; Li et al., 2011; Veyrier et al., 2011; Padilla-Benavides et al., 2013). It is therefore important to call attention to these efflux systems as virulence factors, as they have received less attention than metal importer systems. This article offers a brief perspective of the different families of metallo-exporters and a discussion of their general importance in the virulence of bacterial pathogens with emphasis on Neisseria meningitidis, an obligate human respiratory symbiont.

\section{METAL EFFLUX SYSTEMS}

The concentrations of metals can vary dramatically in the host organism during the course of a bacterial infection, and pathogens have developed a large panel of exporters to regulate their intracellular metal concentrations. Currently five main classes of bacterial exporters (Figure 1) have been described:

1. The Resistance-Nodulation-Cell division (RND) type transporters are integral membrane proteins mediating the efflux of a broad variety of substrates with a subset exporting metals. This subgroup is named heavy-metal efflux RND (HMERND). This tripartite transporter utilizes the proton motive force to drive the efflux of the substrates (Nies, 1995; Goldberg et al., 1999). The RND pump (annotated A in Figure 1) is an integral membrane protein with a hydrophilic periplasmic component, connected to a trimeric outer membrane factor ( $\mathrm{C}$ in Figure 1). This outer membrane channel allows the efflux of metal into the extracellular space (Paulsen et al., 1997). The third part of the RND transporter complex is composed of several units of a periplasmic membrane protein ( $\mathrm{B}$ in Figure 1). It serves as an adaptor that forms a ring around the outer membrane proteins and the pump, thereby stabilizing contact between the two other components (Murakami et al., 2002; Akama et al., 2004a,b). 


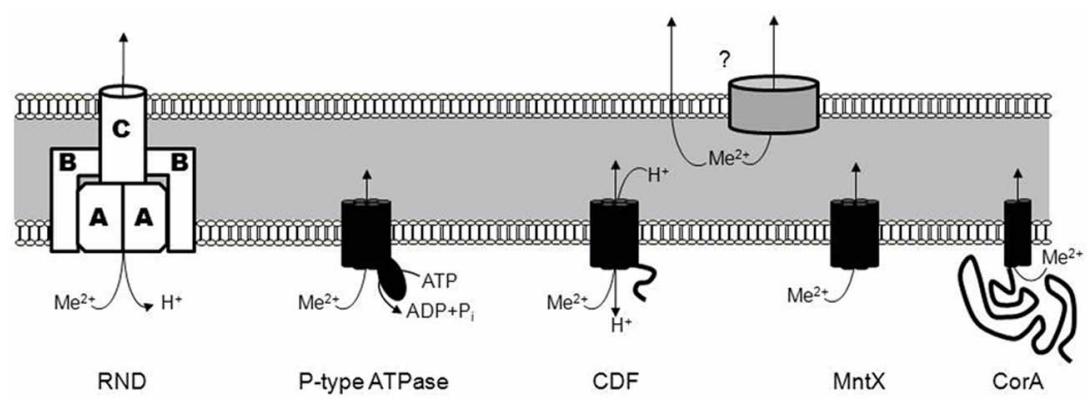

FIGURE 1 | The different families of metal exporters. The different families of metal exporters include the Resistance-Nodulation-Cell division (RND) type transporters, the P-type ATPase family (forming a covalent phosphorylated intermediate), the Cation Diffusion Facilitator (CDF) family, the MntX
(Transporter Mediating Manganese Export) family, and the CorA family (Cobalt Resistance protein A). As schematized by a question-mark, the subsequent export from the periplasm to the extracellular space can be mediated via an unknown porin or passively.
Several RND exporter systems have been identified to date, including CzcABC from Cupriavidus metallidurans which mediates the efflux of $\mathrm{Co}^{2+}, \mathrm{Zn}^{2+}$, and $\mathrm{Cd}^{2+}$ with different affinities. The deletion of $c z c C$ (the outer membrane component) resulted in a decrease of $\mathrm{Cd}^{2+}$ and $\mathrm{Co}^{2+}$ efflux whereas the lack of $c z c A$ or $c z c B$, the pump and fusion protein, respectively, induced a complete loss of efflux activity (Nies and Silver, 1989; Nies et al., 1989; Goldberg et al., 1999). Other characterized RND systems include CnrABC from Alcaligenes eutrophus which mediates the efflux of $\mathrm{Co}^{2+}$ and $\mathrm{Ni}^{2+}$ (Liesegang et al., 1993), CznABC from Helicobacter pylori which mediates resistance against high concentrations of $\mathrm{Ni}^{2+}, \mathrm{Zn}^{2+}$, and $\mathrm{Cd}^{2+}$ (Stahler et al., 2006) and CusABC from $E$. coli which mediates the efflux of $\mathrm{Cu}^{+}$and $\mathrm{Ag}^{+}$(Long et al., 2012).

2. Members of the P-type ATPase family (Figure 1) are present in eukaryotes and prokaryotes and, as the name implies, they couple metal transport to the hydrolysis of ATP (Fagan and Saier, 1994). Catalytic phosphorylation of the transporter occurs after binding of cytoplasmic metal to the trans-membrane metal-binding sites. This phosphorylation is reported to induce a permissive conformation allowing the translocation of metals (Stokes et al., 1999). Two substrate classes have been defined for the family: $\mathrm{Zn}^{2+} / \mathrm{Cd}^{2+} / \mathrm{Pb}^{2+}$ or $\mathrm{Cu}^{+} / \mathrm{Ag}^{+}$. Exporters specific for the former class include $\mathrm{ZntA}$ from E. coli (Rensing et al., 1997), CadA from Bacillus subtilis (Solovieva and Entian, 2002; Gaballa and Helmann, 2003), and CtpC from Mycobacterium tuberculosis (Botella et al., 2011). The second class is exported by homologs of CopA from Streptococcus pneumoniae (Shafeeq et al., 2011). CopA, the $\mathrm{Cu}^{+}$-efflux P-type ATPase, maintains a low cytoplasmic copper concentration in conjunction with other members of a single operon encoding the $\mathrm{Cu}^{+}$-dependent repressor, CopY (Portmann et al., 2006) and CupA, a cell membrane-anchored $\mathrm{Cu}^{+}$-chaperone (Fu et al., 2013). Biochemical characterization of the CopA exporter indicates an eight transmembrane-helix topology forming a $\mathrm{Cu}^{+}$transport channel (Padilla-Benavides et al., 2013).

3. An important and diverse class of metal exporters is the Cation Diffusion Facilitator (CDF) family (Figure 1). CDF members transport various metals in both prokaryotes and eukaryotes (Haney et al., 2005). The first description of a CDF protein was YiiP from E. coli and its function, the efflux of $\mathrm{Cd}^{2+}$ and $\mathrm{Zn}^{2+}$, is coupled to $\mathrm{H}^{+}$antiport. In addition, $\mathrm{Fe}^{2+}$ was also suggested to be exported through YiiP (Grass et al., 2005) but subsequent studies have shown that $\mathrm{Fe}^{2+}$ transport is not as efficient as for $\mathrm{Cd}^{2+}$ and $\mathrm{Zn}^{2+}$ (Wei and $\mathrm{Fu}, 2005$; Hoch et al., 2012). YiiP and other members of the family are usually composed of six transmembrane domains followed by a metallochaperone-like cytoplasmic domain that regulates metal transport activity (Lu et al., 2009). Crystal structures revealed an inward-facing homodimeric structure with four $\mathrm{Zn}^{2+}$ binding sites per monomer, designated $\mathrm{Z1-Z4} \mathrm{(Lu} \mathrm{and}$ Fu, 2007; Coudray et al., 2013). Several homologs with specificity for $\mathrm{Zn}^{2+}$ have been described, including ZitB in E. coli (Chao and Fu, 2004), ZitA in M. tuberculosis (Nies, 2003), CzcD in B. subtilis (Guffanti et al., 2002) or S. pneumoniae (Kloosterman et al., 2007).

A subclass of CDF exporters, MntE, with a preference for $\mathrm{Mn}^{2+}$ has also been described. In general $\mathrm{Mn}$ has been viewed as completely beneficial for the bacteria. For instance, it has been established that Mn plays a role in resistance to superoxide and hydrogen peroxide in several bacteria including S. pneumoniae (Yesilkaya et al., 2000; McAllister et al., 2004) Bradyrhizobium japonicum (Hohle and O'Brian, 2012) and Neisseria gonorrhoeae (Seib et al., 2006) among others. Accordingly $\mathrm{Mn}^{2+}$ importers, e.g., $\mathrm{MntH}$ and MntABC, have received the majority of attention until recently, when MntEdependant $\mathrm{Mn}^{2+}$ export was described in S. pneumoniae (Rosch et al., 2009).

4. Several recent studies have also shown that $\mathrm{MntE}$ is not the only type of $\mathrm{Mn}^{2+}$ exporter and the existence of a new and distinct family corresponding to the fourth type of exporters, was revealed: the MntX (Transporter Mediating Manganese Export) family (Figure 1) (Li et al., 2011; Veyrier et al., 2011). Little is known about the MntX family transport mechanism but secondary structure and topological predictions suggest an inverted repeat of three transmembrane segments, i.e., DUF204 (Veyrier et al., 2011). Unlike the other families, MntX is found exclusively in the bacterial kingdom, indicating the 
family may have a relatively recent origin following the genetic fusion of two DUF204 domains (Veyrier et al., 2011). For the moment, homologs of MntX in N. meningitidis (Veyrier et al., 2011), Xanthomonas sp. (Li et al., 2011; Veyrier et al., 2011), and E. coli (Waters et al., 2011) have all been described to export principally $\mathrm{Mn}^{2+}$ with some secondary affinity for other divalent metals.

5. The fifth exporter family is composed of a subclass of the 2TM-GxN family (CorA, Cobalt Resistance protein A) that was first identified as $\mathrm{Mg}^{2+}$ transporters (Figure 1) (Smith et al., 1993). However, some members are dedicated to the export of other divalent cations, principally $\mathrm{Zn}^{2+}$. $\mathrm{ZntB}$ of Salmonella enterica is involved in the transmembrane flux of $\mathrm{Zn}^{2+}$ and $\mathrm{Cd}^{2+}$ (Worlock and Smith, 2002). This protein, which may multimerize, harbors two transmembrane domains and a long cytoplasmic region that facilitates acquisition and subsequent delivery of cations to the transport channel.

\section{METAL EFFLUX AND VIRULENCE}

As stated before, metal chelation is used by the immune-system to restrict bacterial growth and, by definition, the use of exporters may not help the bacteria in this situation. From the above description, the majority of exporters from bacterial pathogens are dedicated to export of three transition metals $(\mathrm{Zn}, \mathrm{Cu}$, and $\mathrm{Mn})$ that are found in substantial amount in the human body. Interestingly, $\mathrm{Zn}^{2+}$ levels are increased during inflammation (20) and have long been recognized to regulate the immune system (13). In addition, $\mathrm{Zn}^{2+}$ is also present in phagosomes containing bacteria (35). Thus, it is postulated that pathogenic bacteria uses $\mathrm{Zn}^{2+}$ export systems to face the fluctuating levels of $\mathrm{Zn}^{2+}$ during infection of the human body. The same may apply for copper, as it has been recently demonstrated that animals use copper as an anti-microbial weapon by inducing oxidative stress (26). Similarly, $\mathrm{Cu}^{+}$is imported into the phagosome via the protein ATP7A (White et al., 2009). It is therefore not surprising that pathogens lacking $\mathrm{Zn}^{2+}$ or $\mathrm{Cu}^{+}$exporters have impaired virulence. As an example, it has been established that a $\operatorname{cop} A$ mutant strain showed decreased virulence in a mouse model of pneumococcal pneumonia and a decreased ability to survive in the mouse nasopharynx (NP), indicating that $\mathrm{Cu}^{+}$homeostasis plays an important role in S. pneumoniae physiology and virulence (26). All together, these studies suggest that both metals are used by the immune system to intoxicate bacteria (Botella et al., 2012).

The role of $\mathrm{Mn}^{2+}$ during infection is less understood as both beneficial and adverse effects have been reported. Nevertheless, all studies point to a general but important role of $\mathrm{Mn}^{2+}$ export in bacterial pathogenesis. All the pathogens tested to date have a decrease in their virulence when deprived of their $\mathrm{Mn}^{2+}$ exporters. In S. pneumoniae, it was demonstrated that the lack of MntE, belonging to the CDF family, reduced virulence by diminishing both nasal colonization and blood invasion, resulting in decreased mouse mortality (Rosch et al., 2009). The same applies to Xanthomonas oryzae pv. oryzae in a plant model of infection or $N$. meningitidis in a mouse sepsis model of infection after inactivation of their $\mathrm{Mn}^{2+}$ exporter from the MntX family ( $\mathrm{Li}$ et al., 2011; Veyrier et al., 2011). These data could suggest the existence of a host immune strategy based on $\mathrm{Mn}^{2+}$ poisoning. This hypothesis is somewhat discordant with the recent description of a host $\mathrm{Mn}^{2+}$ and $\mathrm{Zn}^{2+}$ chelator, calprotectin (Corbin et al., 2008). This host factor is capable of inhibiting bacterial growth in a $\mathrm{Mn}^{2+}$-dependent manner (Damo et al., 2013), thereby fulfilling an important role in the protection of the host against infection by bacterial pathogens such as S. aureus (Corbin et al., 2008; Damo et al., 2013). Furthermore, the poisoning hypothesis is also in disagreement with the fact that deletion of $\mathrm{Mn}^{2+}$ importers decreases the virulence of several pathogens (Boyer et al., 2002; Anderson et al., 2009; Champion et al., 2011; Perry et al., 2012). For this reason, further study of this phenomenon will be important to understand the exact role that $\mathrm{Mn}^{2+}$ plays during infection (poison, nutrient or both).

\section{METAL EXPORT: THE EXAMPLE OF $N$. meningitidis}

The NP defines the upper part of the pharynx from the end of nasal cavities (choanoe) to the upper surface of the soft palate. On the lateral parts it communicates with the Eustachian tubes by the pharyngeal ostium whereas the posterior part is composed of the pharyngeal tonsils (adenoids). This compartment is open and serves as a habitat for many microorganisms which are collectively called the NP microbiota (or flora). In this sense, the NP is the ecological niche for many bacterial pathogens such as N. meningitidis, S. pneumoniae, Haemophilus influenzae, and Moraxella catarrhalis. While carriage is usually asymptomatic, it can occasionally evolve into local infections of the upper-respiratory tract (pharyngitis, laryngitis, bronchitis, sinusitis, and otitis) or an invasive infection leading to life threatening diseases, such as invasive pneumonia, septicemia, and meningitis. Consequently, this leads to major morbidity and mortality as well as public health and economic burdens.

N. meningitidis is exclusively found in humans and frequently isolated from the upper respiratory tract of asymptomatic carriers (overall $10 \%$ of the general population). It is also the causative agent of life threatening invasive infections such as septicemia and meningitidis. The carriage of N. meningitidis is low in children (around 4-7\%) where the principal neisserial colonizer (around $15 \%$, Cartwright et al., 1987) is a closely related, non-pathogenic species, Neisseria lactamica. The prevalence of $N$. meningitidis increases after 10 years old with a peak at 19 years old (around $24 \%$ ) and decreases throughout adulthood (13\% in 30-year old to $8 \%$ in 50-year old) (Christensen et al., 2011).

The importance of Fe import systems for N. meningitidis virulence has been previously demonstrated following deletion of genes coding for several transporters (Genco et al., 1991; Genco and Desai, 1996; Larson et al., 2002; Renauld-Mongenie et al., 2004; Hagen and Cornelissen, 2006). A complementary approach has been used in which its virulence was enhanced by providing a compatible Fe source (Oftung et al., 1999; Zarantonelli et al., 2007). The role of exporters in the virulence of this nasopharyngeal pathogen is less-well established. The emergence of data concerning the role of exporters as virulence determinants, and the new concept of bacterial metallo-intoxication by the immune system, should encourage future research on this topic.

Our group has recently identified a novel $\mathrm{Mn}^{2+}$-exporter, MntX. We showed the $m n t X$ gene is expressed during sepsis in a 
mouse model and required for full virulence (Veyrier et al., 2011). We have further shown that MntX is required to maintain the $\mathrm{Fe} / \mathrm{Mn}$ ratio thus avoiding molecular replacement between these two metals (Veyrier et al., 2011). Meningococci acquire Fe from host sources such as albumin, transferrin, or Fe-citrate which have also been shown to bind Mn. Therefore, a portion of these molecules is complexed with $\mathrm{Mn}$ in the host (concentration in the $\mu \mathrm{M}$ range) (Michalke et al., 2007). We speculate, based on the well-described needs of N. meningitidis for Fe (Genco et al., 1991; Genco and Desai, 1996; Larson et al., 2002; Renauld-Mongenie et al., 2004; Hagen and Cornelissen, 2006), that the intensive import of Fe could result in non-specific import of other divalent metals, which consequently must be exported. In this sense, we observed a specific $\mathrm{Mn}^{2+}$-export by $\mathrm{MntX}$ of $N$. meningitidis whilst the homologous exporter of $X$. campestris was also able to export $\mathrm{Fe}^{2+}$ to some extent (Veyrier et al., 2011). In this case, metallo-exporters may be required to maintain the optimal ratio between different metals (e.g., $\mathrm{Mn} / \mathrm{Fe}$ and $\mathrm{Mn} / \mathrm{Zn}$ ). Non-specific metal uptake should be also considered as a complementary hypothesis to Mn-intoxication by the host immune system. As another alternative, it has been reported that $N$. meningitidis harbors a specific Mn-dependant hemolysin called HrpA (Michalke et al., 2007). It is therefore possible that MntX (and other exporters) delivers $\mathrm{Mn}^{2+}$ to $N$. meningitidis-specific extracellular virulence factors such as HrpA.
Although N. gonorrhoeae is closely related to N. meningitidis it generally resides asymptomatically in the female genitourinary tract. This ecosystem is more anaerobic than the NP and is also occupied by $\mathrm{H}_{2} \mathrm{O}_{2}$ producing lactobacilli. These features of the genitourinary tract are known to increase bacterial requirement for intracellular $\mathrm{Mn}^{2+}$ and that may explained the high proportion of strains of $N$. gonorrhoeae harboring a premature stop codon mutation in the $m n t X$ gene (Veyrier et al., 2011).

\section{METAL EFFLUX SYSTEMS AND THE EVOLUTION OF $\boldsymbol{N}$. meningitidis}

The discovery of MntX highlights the importance of metal efflux system in the virulence of N. meningitidis. Importantly, the genome of $N$. meningitidis harbors other putative metal exporters. Figure 2A presents the genes with homologies to putative exporters detected in the genomes of $N$. meningitidis and two other major Gram-negative pathogens of the NP: M. catarrhalis and $H$. influenzae. Although the genomes have similar sizes, $N$. meningitidis seems to harbor more efflux systems. Only one gene was common to all three species, NMB1325, which shares a high similarity with HI0290 (81\%) and with MCR_1049 (68\%). As Fe importers are often present in horizontally transferred pathogenicity islands, we wondered if this could be the case for additional metallo-exporters, and if some of them could have been specifically acquired by N. meningitidis. As this bacterium is

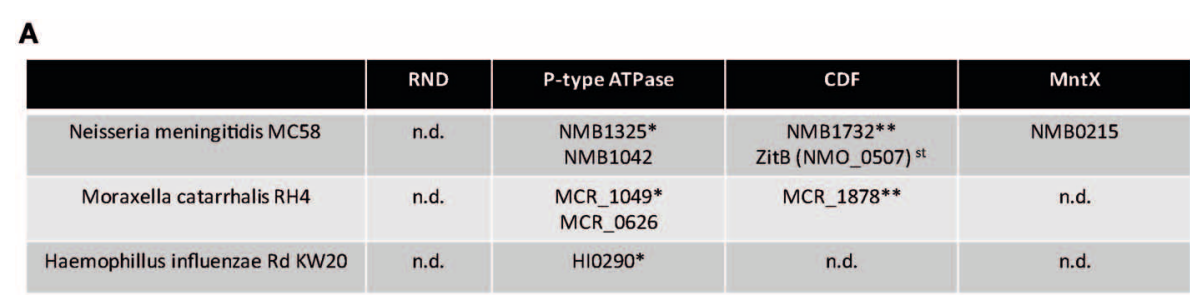

B

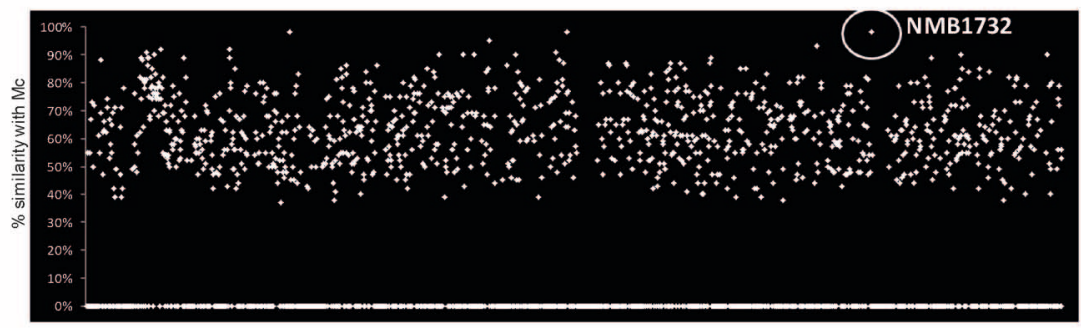

C

N. meningitidis MC58 proteins

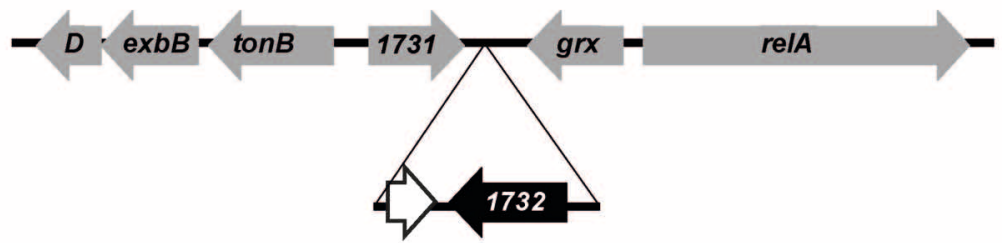

FIGURE 2 | The example of Neisseria meningitidis exporters. (A) Candidate for metal exporters encoded in the genomes of three nasopharyngeal pathogens based on the Kyoto Encyclopedia of Genes and Genomes (KEGG database). st stands for strain specific and n.d. for not detected. ${ }^{*}$ and ${ }^{* *}$ represents groups of putative homologous genes determined using blastp similarity. (B) TBlastN of N. meningitidis MC58 proteins against the genome of $M$. catarrhalis $\mathrm{RH} 4$ (Mc). (C) Gene organization of the NMB1732 locus. The genes in gray have common organization between $N$. meningitidis and $N$. gonorrhoeae whereas the genes in black are N. meningitidis specific. The white gene, adjacent to NMB1732, corresponds to a remnant of DNA methyltransferase also present in the genome of $M$. catarrhalis. 
a human specific nasopharyngeal pathogen, without possibility of survival in the external environment, acquisition of such exporter by horizontal gene transfer (HGT) would support a role of these exporters in the emergence of $N$. meningitidis.

With the exception of NMB1732, all the putative exporters identified have homologs in other Neisseria species, and therefore cannot represent examples of recent HGT. NMB1732 is rarely present (if ever) in the genomes of other Neisseria species (such as $N$. gonorrhoeae) nor in other closely related non-neisseria strains (e.g., Kingella). In addition, all the isolates of N. meningitidis sequenced to date $(\sim 200)$ harbor this gene, coding for a protein from the CDF family. As a consequence, this $N$. meningitidis specific gene is used by the Centre National de Reference des Meningocoques (CNRM) that is located within our laboratory, at the Institut Pasteur in Paris, to definitively distinguish N. meningitidis from all the other Neisseria species by PCR. Surprisingly, this gene and the surrounding region have an unusually high identity (99\%) with a region of the genome of the non-closely related $M$. catarrhalis (Figure $2 \mathbf{B}$ ) which shares the same ecosystem. Moreover, the gene is also present in other Moraxella species. Altogether, these findings suggest a possible transfer of the CDF exporter NMB1732 from M. catarrhalis to N. meningitidis. Our hypothesis is reinforced by the fact that, with the exception of NMB1732 and the adjacent pseudogene, the organization of the locus (including ton $B$ ) is conserved between $N$. meningitidis and other closely related Neisseria species (Figure 2C). The importance of MntX for $N$. meningitidis virulence and the acquisition by HGT and the conservation of NMB1732, a putative CDF exporter, highlight the pathogen's needs for metal exporters and the role that these exporters have played in the emergence of pathogens.

\section{CONCLUSION}

The existence of exporters and their transfer between species has been known for a long time in the context of bacterial living in the environment. In the last few years, bacterial metallo-exporters have also been demonstrated to play a role in the context of infection. The immune system uses $\mathrm{Cu}^{+/ 2+}$ or $\mathrm{Zn}^{2+}$ to poison bacteria and export systems are used to detoxify this overload. The role of $\mathrm{Mn}$ is not yet completely understood, but MntE and MntX are the proof of concept that $\mathrm{Mn}^{2+}$ exporters are important for pathogenesis. Nevertheless, further research is required to understand the role of exporters in emergence and adaptation of pathogens and how these efflux systems can be used to thwart the host immune system defenses.

\section{REFERENCES}

Akama, H., Kanemaki, M., Yoshimura, M., Tsukihara, T., Kashiwagi, T., Yoneyama, H., et al. (2004a). Crystal structure of the drug discharge outer membrane protein, OprM, of Pseudomonas aeruginosa: dual modes of membrane anchoring and occluded cavity end. J. Biol. Chem. 279, 52816-52819. doi: $10.1074 /$ jbc.C400445200

Akama, H., Matsuura, T., Kashiwagi, S., Yoneyama, H., Narita, S., Tsukihara, T., et al. (2004b). Crystal structure of the membrane fusion protein, MexA, of the multidrug transporter in Pseudomonas aeruginosa. J. Biol. Chem. 279, 25939-25942. doi: 10.1074/jbc.C400164200

Anderson, E. S., Paulley, J. T., Gaines, J. M., Valderas, M. W., Martin, D. W., Menscher, E., et al. (2009). The manganese transporter MntH is a critical virulence determinant for brucella abortus 2308 in experimentally infected mice. Infect. Immun. 77, 3466-3474. doi: 10.1128/IAI.00444-09
Barondeau, D. P., and Getzoff, E. D. (2004). Structural insights into proteinmetal ion partnerships. Curr. Opin. Struct. Biol. 14, 765-774. doi: 10.1016/j.sbi.2004.10.012

Botella, H., Peyron, P., Levillain, F., Poincloux, R., Poquet, Y., Brandli, I., et al. (2011). Mycobacterial $\mathrm{p}$ (1)-type ATPases mediate resistance to zinc poisoning in human macrophages. Cell Host Microbe 10, 248-259. doi: 10.1016/j.chom.2011.08.006

Botella, H., Stadthagen, G., Lugo-Villarino, G., de Chastellier, C., and Neyrolles, O. (2012). Metallobiology of host-pathogen interactions: an intoxicating new insight. Trends Microbiol. 20, 106-112. doi: 10.1016/j.tim.2012.01.005

Boyer, E., Bergevin, I., Malo, D., Gros, P., and Cellier, M. F. (2002). Acquisition of $\mathrm{Mn}(\mathrm{II})$ in addition to $\mathrm{Fe}(\mathrm{II})$ is required for full virulence of Salmonella enterica serovar Typhimurium. Infect. Immun. 70, 6032-6042. doi: 10.1128/IAI.70.11.6032-6042.2002

Canonne-Hergaux, F., Gruenheid, S., Govoni, G., and Gros, P. (1999). The Nramp1 protein and its role in resistance to infection and macrophage function. Proc. Assoc. Am. Physicians 111, 283-289. doi: 10.1046/j.1525-1381.1999.99236.x

Cartwright, K. A., Stuart, J. M., Jones, D. M., and Noah, N. D. (1987). The Stonehouse survey: nasopharyngeal carriage of meningococci and Neisseria lactamica. Epidemiol. Infect. 99, 591-601. doi: 10.1017/S0950268800066449

Champion, O. L., Karlyshev, A., Cooper, I. A., Ford, D. C., Wren, B. W., Duffield, M., et al. (2011). Yersinia pseudotuberculosis $\mathrm{mntH}$ functions in intracellular manganese accumulation, which is essential for virulence and survival in cells expressing functional Nramp1. Microbiology 157, 1115-1122. doi: 10.1099/mic.0.045807-0

Chao, Y., and Fu, D. (2004). Kinetic study of the antiport mechanism of an Escherichia coli zinc transporter, ZitB. J. Biol. Chem. 279, 12043-12050. doi: 10.1074/jbc.M313510200

Christensen, H., May, M., Bowen, L., Hickman, M., and Trotter, C. L. (2011). Meningococcal carriage by age: a systematic review and meta-analysis. Lancet Infect. Dis. 10, 853-861. doi: 10.1016/S1473-3099(10)70251-6

Corbin, B. D., Seeley, E. H., Raab, A., Feldmann, J., Miller, M. R., Torres, V. J., et al. (2008). Metal chelation and inhibition of bacterial growth in tissue abscesses. Science 319, 962-965. doi: 10.1126/science.1152449

Coudray, N., Valvo, S., Hu, M., Lasala, R., Kim, C., Vink, M., et al. (2013). Inward-facing conformation of the zinc transporter YiiP revealed by cryoelectron microscopy. Proc. Natl. Acad. Sci. U.S.A. 110, 2140-2145. doi: 10.1073/pnas.1215455110

Damo, S. M., Kehl-Fie, T. E., Sugitani, N., Holt, M. E., Rathi, S., Murphy, W. J., et al. (2013). Molecular basis for manganese sequestration by calprotectin and roles in the innate immune response to invading bacterial pathogens. Proc. Natl. Acad. Sci. U.S.A. 110, 3841-3846. doi: 10.1073/pnas.1220341110

Fagan, M. J., and Saier, M. H., JR. (1994). P-type ATPases of eukaryotes and bacteria: sequence analyses and construction of phylogenetic trees. J. Mol. Evol. 38, 57-99. doi: 10.1007/BF00175496

Finkelstein, R. A., Sciortino, C. V., and McIntosh, M. A. (1983). Role of iron in microbe-host interactions. Rev. Infect. Dis. 5(Suppl. 4), S759-S777. doi: 10.1093/clinids/5.Supplement_4.S759

Fu, Y., Tsui, H. C., Bruce, K. E., Sham, L. T., Higgins, K. A., Lisher, J. P., et al. (2013). A new structural paradigm in copper resistance in Streptococcus pneumoniae. Nat. Chem. Biol. 9, 177-183. doi: 10.1038/nchembio.1168

Gaballa, A., and Helmann, J. D. (2003). Bacillus subtilis CPx-type ATPases: characterization of Cd, Zn, Co and Cu efflux systems. Biometals 16, 497-505. doi: 10.1023/A:1023425321617

Genco, C. A., Chen, C. Y., Arko, R. J., Kapczynski, D. R., and Morse, S. A. (1991). Isolation and characterization of a mutant of Neisseria gonorrhoeae that is defective in the uptake of iron from transferrin and haemoglobin and is avirulent in mouse subcutaneous chambers. J. Gen. Microbiol. 137, 1313-1321. doi: 10.1099/00221287-137-6-1313

Genco, C. A., and Desai, P. J. (1996). Iron acquisition in the pathogenic Neisseria. Trends Microbiol. 4, 179-184. doi: 10.1016/0966-842X(96)10029-9

Goldberg, M., Pribyl, T., Juhnke, S., and Nies, D. H. (1999). Energetics and topology of CzcA, a cation/proton antiporter of the resistance-nodulation-cell division protein family. J. Biol. Chem. 274, 26065-26070. doi: 10.1074/jbc.274.37. 26065

Grass, G., Otto, M., Fricke, B., Haney, C. J., Rensing, C., Nies, D. H., et al. (2005). FieF (YiiP) from Escherichia coli mediates decreased cellular accumulation of iron and relieves iron stress. Arch. Microbiol. 183, 9-18. doi: 10.1007/s00203004-0739-4 
Guffanti, A. A., Wei, Y., Rood, S. V., and Krulwich, T. A. (2002). An antiport mechanism for a member of the cation diffusion facilitator family: divalent cations efflux in exchange for $\mathrm{K}+$ and $\mathrm{H}+$. Mol. Microbiol. 45, 145-153. doi: 10.1046/j.1365-2958.2002.02998.x

Hagen, T. A., and Cornelissen, C. N. (2006). Neisseria gonorrhoeae requires expression of TonB and the putative transporter TdfF to replicate within cervical epithelial cells. Mol. Microbiol. 62, 1144-1157. doi: 10.1111/j.13652958.2006.05429.x

Haney, C. J., Grass, G., Franke, S., and Rensing, C. (2005). New developments in the understanding of the cation diffusion facilitator family. J. Ind. Microbiol. Biotechnol. 32, 215-226. doi: 10.1007/s10295-005-0224-3

Hoch, E., Lin, W., Chai, J., Hershfinkel, M., Fu, D., and Sekler, I. (2012). Histidine pairing at the metal transport site of mammalian $\mathrm{ZnT}$ transporters controls Zn2+ over Cd2+ selectivity. Proc. Natl. Acad. Sci. U.S.A. 109, 7202-7207. doi: 10.1073/pnas. 1200362109

Hohle, T. H., and O'Brian, M. R. (2012). Manganese is required for oxidative metabolism in unstressed Bradyrhizobium japonicum cells. Mol. Microbiol. 84, 766-777. doi: 10.1111/j.1365-2958.2012.08057.x

Kloosterman, T. G., van der Kooi-Pol, M. M., Bijlsma, J. J., and Kuipers, O. P. (2007). The novel transcriptional regulator SczA mediates protection against $\mathrm{Zn} 2+$ stress by activation of the $\mathrm{Zn} 2+$-resistance gene $\mathrm{czcD}$ in Streptococcus pneumoniae. Mol. Microbiol. 65, 1049-1063. doi: 10.1111/j.13652958.2007.05849.x

Larson, J. A., Higashi, D. L., Stojiljkovic, I., and So, M. (2002). Replication of Neisseria meningitidis within epithelial cells requires TonB-dependent acquisition of host cell iron. Infect. Immun. 70, 1461-1467. doi: 10.1128/IAI.70.3.14611467.2002

Li, C., Tao, J., Mao, D., and He, C. (2011). A. novel manganese efflux system, YebN, is required for virulence by Xanthomonas oryzae pv. oryzae. PLoS ONE 6:e21983. doi: 10.1371/journal.pone.0021983

Liesegang, H., Lemke, K., Siddiqui, R. A., and Schlegel, H. G. (1993). Characterization of the inducible nickel and cobalt resistance determinant $\mathrm{cnr}$ from pMOL28 of Alcaligenes eutrophus CH34. J. Bacteriol. 175, 767-778.

Long, F., Su, C. C., Lei, H. T., Bolla, J. R., Do, S. V., and Yu, E. W. (2012). Structure and mechanism of the tripartite CusCBA heavy-metal efflux complex. Philos. Trans. R. Soc. Lond. B. Biol. Sci. 367, 1047-1058. doi: 10.1098/rstb.2011.0203

Lu, M., Chai, J., and Fu, D. (2009). Structural basis for autoregulation of the zinc transporter YiiP. Nat. Struct. Mol. Biol. 16, 1063-1067. doi: 10.1038/nsmb.1662

Lu, M., and Fu, D., (2007). Structure of the zinc transporter YiiP. Science 317, 1746-1748. doi: 10.1126/science. 1143748

McAllister, L. J., Tseng, H. J., Ogunniyi, A. D., Jennings, M. P., McEwan, A. G., and Paton, J. C., (2004). Molecular analysis of the psa permease complex of Streptococcus pneumoniae. Mol. Microbiol. 53, 889-901. doi: 10.1111/j.13652958.2004.04164.x

Michalke, B., Berthele, A., Mistriotis, P., Ochsenkuhn-Petropoulou, M., and Halbach, S., (2007). Manganese species from human serum, cerebrospinal fluid analyzed by size exclusion chromatography-, capillary electrophoresis coupled to inductively coupled plasma mass spectrometry. J. Trace Elem. Med. Biol. 21(Suppl. 1), 4-9. doi: 10.1016/j.jtemb.2007.09.004

Murakami, S., Nakashima, R., Yamashita, E., and Yamaguchi, A., (2002). Crystal structure of bacterial multidrug efflux transporter AcrB. Nature 419, 587-593. doi: $10.1038 /$ nature 01050

Nies, D. H. (1995). The cobalt, zinc, and cadmium efflux system CzcABC from Alcaligenes eutrophus functions as a cation-proton antiporter in Escherichia coli. J. Bacteriol. 177, 2707-2712.

Nies, D. H. (2003). Efflux-mediated heavy metal resistance in prokaryotes. FEMS Microbiol. Rev. 27, 313-339. doi: 10.1016/S0168-6445(03)00048-2

Nies, D. H., Nies, A., Chu, L., and Silver, S. (1989). Expression and nucleotide sequence of a plasmid-determined divalent cation efflux system from Alcaligenes eutrophus. Proc. Natl. Acad. Sci. U.S.A. 86, 7351-7355. doi: 10.1073/pnas.86.19.7351

Nies, D. H., and Silver, S. (1989). Plasmid-determined inducible efflux is responsible for resistance to cadmium, zinc, and cobalt in Alcaligenes eutrophus. J. Bacteriol. 171, 896-900.

Oftung, F., Lovik, M., Andersen, S. R., Froholm, L. O., and Bjune, G. (1999). A mouse model utilising human transferrin to study protection against Neisseria meningitidis serogroup B induced by outer membrane vesicle vaccination. FEMS Immunol. Med. Microbiol. 26, 75-82. doi: 10.1111/j.1574695X.1999.tb01374.x
Padilla-Benavides, T., Long, J. E., Raimunda, D., Sassetti, C. M., and Arguello, J. M. (2013). A novel P(1B)-type Mn2+-transporting ATPase is required for secreted protein metallation in mycobacteria. J. Biol. Chem. 288, 11334-11347. doi: 10.1074/jbc.M112.448175

Padilla-Benavides, T., McCann, C. J., and Arguello, J. M. (2013). The mechanism of $\mathrm{Cu}+$ transport ATPases: interaction with $\mathrm{CU}+$ chaperones and the role of transient metal-binding sites. J. Biol. Chem. 288, 69-78. doi: 10.1074/jbc.M112.420810

Paulsen, I. T., Park, J. H., Choi, P. S., and Saier, M. H. Jr. (1997). A family of gram-negative bacterial outer membrane factors that function in the export of proteins, carbohydrates, drugs and heavy metals from gram-negative bacteria. FEMS Microbiol. Lett. 156, 1-8. doi: 10.1016/S0378-1097(97)00379-0

Perry, R. D., Craig, S. K., Abney, J., Bobrov, A. G., Kirillina, O., Mier, I., et al. (2012). Manganese transporters Yfe and $\mathrm{MntH}$ are Fur-regulated and important for the virulence of Yersinia pestis. Microbiology 158, 804-815. doi: 10.1099/mic.0.053710-0

Portmann, R., Poulsen, K. R., Wimmer, R., and Solioz, M. (2006). CopY-like copper inducible repressors are putative "winged helix" proteins. Biometals 19, 61-70. doi: 10.1007/s10534-005-5381-3

Renauld-Mongenie, G., Poncet, D., Mignon, M., Fraysse, S., Chabanel, C., Danve, B., et al. (2004). Role of transferrin receptor from a Neisseria meningitidis tbpB isotype II strain in human transferrin binding and virulence. Infect. Immun. 72, 3461-3470. doi: 10.1128/IAI.72.6.3461-3470.2004

Rensing, C., Mitra, B., and Rosen, B. P. (1997). The zntA gene of Escherichia coli encodes a $\mathrm{Zn}$ (II)-translocating P-type ATPase. Proc. Natl. Acad. Sci. U.S.A. 94, 14326-14331. doi: 10.1073/pnas.94.26.14326

Rosch, J. W., Gao, G., Ridout, G., Wang, Y. D., and Tuomanen, E. I. (2009). Role of the manganese efflux system mntE for signalling and pathogenesis in Streptococcus pneumoniae. Mol. Microbiol. 72, 12-25. doi: 10.1111/j.13652958.2009.06638.x

Schaible, U. E., and Kaufmann, S. H. (2005). A nutritive view on the host-pathogen interplay. Trends Microbiol. 13, 373-380. doi: 10.1016/j.tim.2005.06.009

Seib, K. L., Wu, H. J., Kidd, S. P., Apicella, M. A., Jennings, M. P., and McEwan, A. G. (2006). Defenses against oxidative stress in Neisseria gonorrhoeae: a system tailored for a challenging environment. Microbiol. Mol. Biol. Rev. 70, 344-361. doi: 10.1128/MMBR.00044-05

Shafeeq, S., Yesilkaya, H., Kloosterman, T. G., Narayanan, G., Wandel, M., Andrew, P. W., et al. (2011). The cop operon is required for copper homeostasis and contributes to virulence in Streptococcus pneumoniae. Mol. Microbiol. 81, 1255-1270. doi: 10.1111/j.1365-2958.2011.07758.x

Smith, R. L., Banks, J. L., Snavely, M. D., and Maguire, M. E. (1993). Sequence and topology of the CorA magnesium transport systems of Salmonella typhimurium and Escherichia coli. Identification of a new class of transport protein. J. Biol. Chem. 268, 14071-14080.

Solovieva, I. M., and Entian, K. D. (2002). Investigation of the yvgW bacillus subtilis chromosomal gene involved in $\mathrm{Cd}(2+)$ ion resistance. FEMS Microbiol. Lett. 208, 105-109. doi: 10.1111/j.1574-6968.2002.tb11068.x

Stadtman, E. R. (1990). Metal ion-catalyzed oxidation of proteins: biochemical mechanism and biological consequences. Free Radic. Biol. Med. 9, 315-325. doi: 10.1016/0891-5849(90)90006-5

Stahler, F. N., Odenbreit, S., Haas, R., Wilrich, J., Van Vliet, A. H., Kusters, J. G., et al. (2006). The novel Helicobacter pylori CznABC metal efflux pump is required for cadmium, zinc, and nickel resistance, urease modulation, and gastric colonization. Infect. Immun. 74, 3845-3852. doi: 10.1128/IAI.02025-05

Stokes, D. L., Auer, M., Zhang, P., and Kuhlbrandt, W. (1999). Comparison of H+ATPase and $\mathrm{Ca} 2+-$ ATPase suggests that a large conformational change initiates P-type ion pump reaction cycles. Curr. Biol. 9, 672-679. doi: 10.1016/S09609822(99)80307-8

Veyrier, F. J., Boneca, I. G., Cellier, M. F., and Taha, M. K. (2011). A novel metal transporter mediating manganese export ( $\mathrm{MntX})$ regulates the $\mathrm{Mn}$ to $\mathrm{Fe}$ intracellular ratio and Neisseria meningitidis virulence. PLoS Pathog. 7:e1002261. doi: 10.1371/journal.ppat.1002261

Waters, L. S., Sandoval, M., and Storz, G. (2011). The Escherichia coli MntR miniregulon includes genes encoding a small protein and an efflux pump required for manganese homeostasis. J. Bacteriol. 193, 5887-5897. doi: 10.1128/JB.05872-11

Wei, Y., and Fu, D. (2005). Selective metal binding to a membrane-embedded aspartate in the Escherichia coli metal transporter YiiP (FieF). J. Biol. Chem. 280, 33716-33724. doi: 10.1074/jbc.M506107200 
Weinberg, E. D. (1971). Role of iron in host-parasite interactions. J. Infect. Dis. 124, 401-410. doi: 10.1093/infdis/124.4.401

White, C., Lee, J., Kambe, T., Fritsche, K., and Petris, M. J. (2009). A role for the ATP7A copper-transporting ATPase in macrophage bactericidal activity. J. Biol. Chem. 284, 33949-33956. doi: 10.1074/jbc.M109. 070201

Worlock, A. J., and Smith, R. L. (2002). ZntB is a novel Zn2+ transporter in Salmonella enterica serovar Typhimurium. J. Bacteriol. 184, 4369-4373. doi: 10.1128/JB.184.16.4369-4373.2002

Yesilkaya, H., Kadioglu, A., Gingles, N., Alexander, J. E., Mitchell, T. J., and Andrew, P. W. (2000). Role of manganese-containing superoxide dismutase in oxidative stress and virulence of Streptococcus pneumoniae. Infect. Immun. 68, 2819-2826. doi: 10.1128/IAI.68.5.2819-2826.2000

Zarantonelli, M. L., Szatanik, M., Giorgini, D., Hong, E., Huerre, M., Guillou, F., et al. (2007). Transgenic mice expressing human transferrin as a model for meningococcal infection. Infect. Immun. 75, 5609-5614. doi: 10.1128/IAI.00781-07
Conflict of Interest Statement: The authors declare that the research was conducted in the absence of any commercial or financial relationships that could be construed as a potential conflict of interest.

Received: 16 October 2013; paper pending published: 08 November 2013; accepted: 05 December 2013; published online: 23 December 2013.

Citation: Guilhen C, Taha $M-K$ and Veyrier FJ (2013) Role of transition metal exporters in virulence: the example of Neisseria meningitidis. Front. Cell. Infect. Microbiol. 3:102. doi: 10.3389/fcimb.2013.00102

This article was submitted to the journal Frontiers in Cellular and Infection Microbiology.

Copyright (c) 2013 Guilhen, Taha and Veyrier. This is an open-access article distributed under the terms of the Creative Commons Attribution License (CC BY). The use, distribution or reproduction in other forums is permitted, provided the original author(s) or licensor are credited and that the original publication in this journal is cited, in accordance with accepted academic practice. No use, distribution or reproduction is permitted which does not comply with these terms. 